\title{
Polifenóis totais e flavonoides em amostras de chá verde (Camellia sinensis L.) de diferentes marcas comercializadas na cidade de Salvador-BA
}

\author{
FIRMINO, L.A. ${ }^{*} ;$ MIRANDA, M.P.S ${ }^{2}$
}

${ }_{1}$ Programa de pós graduação em Ciência de Alimentos - Faculdade de Farmácia Universidade Federal da Bahia - Av. Barão de Geremoabo, s/n - Ondina, Salvador-BA - Brasil - CEP: 40.170-115. 2 Universidade Federal da Bahia, Departamento de Análises Bromatológicas, Faculdade de Farmácia, Av. Barão de Geremoabo, s/n Ondina, Salvador-BA-Brasil - CEP: 40.170-115. *Autor para correspondência: luziana_azevedo@yahoo.com.br

\begin{abstract}
RESUMO: Camellia sinensis é amplamente conhecida por seus efeitos benéficos à saúde humana. Dentre as diversas formas de processamento desta erva, o chá verde e chá preto são os mais populares. Neste trabalho objetivou-se avaliar os teores de fenólicos totais e flavonoides em amostras de 25 diferentes marcas disponíveis à venda em farmácias e supermercados de Salvador-Ba. Os resultados obtidos apresentaram diferenças significativas na concentração dos compostos fenólicos entre as marcas de chá verde estudadas. No estudo também ficou comprovado que, no preparo do chá verde, as amostras obtidas por infusão aquosa com agitação mecânica apresentaram maiores teores de polifenóis e flavonoides em relação àquelas que não foram submetidas à agitação.
\end{abstract}

Palavras-chave: Camellia sinensis, bioativos, antioxidante, chá verde, infusão.

\begin{abstract}
Contents of phenolics and flavonoids in green tea (Camellia sinensis) from samples of different brands available for sale in Salvador-Ba. Camellia sinensis is widely known for its beneficial effects to human health. Among the various forms of processing this herb, the green and the black tea are the most popular ones. The objective of this work was to evaluate the contents of total polyphenol and flavonoids in samples of 25 different brands available for sale in pharmacies and supermarkets of Salvador-Ba. The results showed great variation in the concentration of phenolic compounds among the brands of green tea which were tested. In the study it was also proven that in the green tea preparation the samples obtained by mechanical agitation with aqueous infusion showed higher levels of phenolics and flavonoids contents than those which were not subjected to stirring.
\end{abstract}

Keyworks: Camellia sinensis, bioactive, antioxidant, green tea, water infusion.

\section{INTRODUÇÃO}

A sociedade atual tem buscado na natureza hábitos mais saudáveis de vida. Essa tendência tem levado ao aumento progressivo da produção e utilização dos produtos naturais e consequentemente, maiores preocupações em relação à qualidade destes produtos (Rocha et. al. 2004; Lima et al. 2009; Vuong et al. 2011). Dentre estes se destacam os chás, uma das bebidas mais consumidas no mundo (Asolini et al. 2006).

Apresentando marcante atividade antioxidante, a planta Camellia sinensis, pertencente à família Theaceae, é conhecida popularmente por chá verde (Matsubara \& Rodriguez-Amaya, 2006b; Chen et al. 2010).

Para obtenção do chá, são utilizadas as folhas secas e os brotos da planta (Peron et. al. 2008). Os chás produzidos a partir da planta Camellia sinensis são classificados em três categorias conforme o processo de fabricação: fermentado (preto), o semi-fermentado (oolong) e não-fermentado (verde) (Tanaka \& Kouno, 2003; Soares, 2002; Matsubara \& Rodriguez-Amaya, 2006a).

A composição química dos chás pode variar quanto à espécie, idade das folhas, estação, clima (umidade, temperatura, latitude) e condições de cultivo (solo, água, minerais, fertilizantes, entre outros) (Jayasekera et al. 2011; Scotti et al. 2007). Essas diferenças na matéria-prima refletem no sabor, cor e, 
possivelmente, nos teores de flavonoides (Matsubara \& Rodriguez-Amaya, 2006a). Estes últimos são alguns dos principais componentes químicos antioxidantes da Camellia sinensis, sendo estes potentes quelantes de metais e inibidores da lipoperoxidação Peron et. al. (2008).

A qualidade do chá verde é fortemente influenciada pelos componentes orgânicos e inorgânicos das folhas jovens e dos brotos, os quais são alterados durante a sua transformação (aquecimento) em substâncias que determinam o sabor (Lima et al., 2009). Além disso, a cor, o sabor e o aroma do chá verde estão diretamente associados à quantidade de polifenóis presentes que são os principais compostos que definem sua qualidade (Friedman et al., 2009; Machado \& Bastos, 2007; Scotti et al., 2007; Lima et al., 2009; Soares, 2002).

Segundo Nishiyama et al. (2010) os estudos do chá verde brasileiro (Camellia sinensis) ainda são escassos quando comparados aos realizados com chás verdes produzidos e comercializados em outros países. Além disso, de acordo com Lima et al. (2009) na ultima década o chá verde produzido no Brasil, para exportação, apresentava baixa qualidade e era vendido para formação de blend (mistura), mas nos últimos anos através do plantio de genótipos melhorados e de processamento mais adequados, tem sido possível obter um produto de qualidade superior.

Apesar do mercado para os produtos naturais ser promissor e de demanda crescente, a falta de qualidade, desde a matéria-prima ao produto acabado é um problema frequente, devido a fatores, como o armazenamento inadequado, que além de gerar perda de princípios ativos do produto pode favorecer a contaminação por agentes diversos, que por sua vez podem causar danos à saúde do consumidor, além de determinar prejuízos econômicos (Bugno et. al., 2005; Veiga Junior et al., 2005; França et. al., 2008).

Tendo em vista que um dos principais atrativos no consumo do chá verde é seu potencial de atividade antioxidante o qual é desempenhado principalmente pelos polifenóis, e estes últimos são um indicativo da qualidade desta matéria prima vegetal, pois as diferenças na quantidade de fenólicos podem acarretar uma grande variação nos efeitos esperados para estes produtos, este estudo teve por finalidade determinar o teor de polifenóis totais e flavonoides, em infusões preparadas a partir de amostras de diferentes marcas comercializadas em farmácias e supermercados de Salvador-Ba e verificar o peso do produto seco de acordo com as normas da legislação vigente.

\section{MATERIAL E MÉTODOS}

Amostras de 14 diferentes marcas de chá verde (Camellia sinensis (L.) Kuntze) em sachê (saquinhos embalados individualmente e em caixas) e 11 marcas a granel (folhas soltas em pacotes para fracionamento posterior) disponíveis no comércio foram adquiridas no período de janeiro/ 2009 a janeiro/ 2010 em farmácias e supermercados da cidade de Salvador-BA.

Para facilitar a avaliação dos teores reais de polifenóis totais e flavonoides a serem ingeridos pelos consumidores dos chás, todos os extratos foram preparados na forma de infusão aquosa e analisados no mesmo dia.

Foram preparadas infusões sem agitação e submetidas à agitação por 30 segundos em vortex, utilizando $10 \mathrm{~mL}$ de água, após a mesma atingir a temperatura de ebulição, adicionado $0,1 \mathrm{~g}$ das folhas do chá e deixados em infusão por 10 minutos (Ramirez-Mares et al., 2004).

A quantificação dos compostos fenólicos totais foi realizada, em triplicata, através do método espectrofotométrico utilizando o reagente de Folin-Ciocalteau (marca comercial Merck), tendo epicatequina como padrão de referência e a absorbância foi registrada a $760 \mathrm{~nm}$. Os resultados foram expressos em miligrama $(\mathrm{mg})$ de epicatequina (marca comercial Sigma) equivalentes a quantidade em grama (g) de peso seco da planta ( $\mathrm{mg} \mathrm{Ec/g}$ ) (Singleton \& Rossi, 1965).

A quantificação do teor de flavonoides foi feita através de uma curva de calibração construída pela diluição de uma solução padrão de epicatequina (Ec) $\left(R^{2}=0,9995\right)$ e os resultados foram expressos em mg Ec. $100 \mathrm{~g}^{-1}$, para tal foi utilizado um balão volumétrico de $10 \mathrm{~mL}$, no qual foi adicionado sequencialmente $4 \mathrm{~mL}$ de água destilada, $1 \mathrm{~mL}$ da amostra, $0,3 \mathrm{~mL}$ de nitrito de sódio $5 \%$, após 5 minutos adicionou-se $0,3 \mathrm{~mL}$ do cloreto de alumínio $10 \%$, após 1 minuto adicionou-se $2 \mathrm{~mL}$ de hidróxido de sódio $1 \mathrm{M}$. Completou-se o volume do balão com água destilada e homogeneizou-se manualmente. A absorbância foi medida a 510nm (Lee et al., 2003).

A massa individual das amostras em sachê foi determinada, para cada marca 5 sachês foram utilizados para a determinação do peso médio e cálculo do teor real de polifenóis totais e flavonoides de acordo com a proporção de erva seca e água indicada na embalagem de cada fabricante.

\section{ANÁLISE ESTATÍSTICA}

Os dados foram submetidos à análise de variância ANOVA. Diferenças significativas entre as medias foram determinadas pelo teste de Tukey ao nível de $p<0,05$. 


\section{RESULTADOS E DISCUSSÃO}

A qualidade do chá representa o parâmetro mais importante para um produto se destacar frente a constante busca por melhoria dos índices de produtividade e de rentabilidade (Ravichandran \& Parthiban, 1998; Owuor et al., 2006).

Segundo Braga et al. (2007), para a maioria das plantas comercializadas na forma de chá não existem parâmetros de avaliação de qualidade, embora sejam amplamente comercializadas em mercados, feiras livres, farmácias e ervanárias brasileiras. Por este pressuposto torna-se prioritário a criação padrões mínimos de qualidade organolépticas, físico-químicas, microbiológicas e de bioativos que venham atender o mercado consumidor brasileiro.

Vários trabalhos utilizam agitação mecânica durante o preparo dos extratos, porém, em todas as embalagens dos chás utilizados neste trabalho não há recomendação para agitação. A orientação exibida nas embalagens é que a erva fique em infusão de forma estática durante 3 a 10 minutos ou até adquirir a coloração e o sabor característicos do chá.

De acordo com Perva-Uzunalic et al. (2006), a combinação mais eficiente para extração dos compostos fenólicos em ervas é uma temperatura inicial de infusão de 95 a $100^{\circ} \mathrm{C}$ e tempo de 5 a 10 minutos. Ainda de acordo com Lima et al. (2004) a maior quantidade de fenólicos obtida do chá preto (Camellia sinensis) ocorreu no tempo de infusão de 10 minutos.

Neste trabalho foram encontradas diferenças significativas nos teores de polifenóis totais e flavonoides entre as marcas avaliadas, em relação aos tipos de amostras (a granel ou sachês) e também quanto ao método de preparo do extrato (submetido ou não à agitação mecânica) conforme as tabelas 1, 2, 3 e 4 .

Nas amostras a granel (Tabela 1), preparadas sob agitação os polifenóis totais variaram de 23,75 a $65,71 \mathrm{mg} / \mathrm{g}$ da planta seca em equivalentes a epicatequina $(\mathrm{mg} / \mathrm{gEc})$, enquanto nas amostras sem agitação a variação foi de 6,34 a $42,71 \mathrm{mg} / \mathrm{gEc}$.

Os teores de flavonoides em amostras de chá verde a granel (Tabela 2) variaram de 9,41 a $28,62 \mathrm{mg} / \mathrm{gEc}$ no extrato obtido com agitação e de 3,70 a 13,31 mg/gEc, quando não houve agitação.

As amostras dos sachês apresentaram teores de polifenóis totais (Tabela 3 ) variando de 30,13 a $63,99 \mathrm{mg} / \mathrm{gEc}$ quando preparadas sob agitação e de 23,18 a 52,65 mg/gEc na ausência de agitação.

Estes resultados corroboram com os de Nishiyama et al. (2010), no qual o autor, também, encontrou diferença significativa nos teores de polifenóis totais entre os extratos aquosos preparados com amostras sob agitação e sem agitação.

Com relação aos flavonoides, o teores encontrados (Tabela 4) variaram de 6,37 a 16,41 $\mathrm{mg} / \mathrm{gEc}$ no extrato obtido sem agitação e de 14,29 a $28,23 \mathrm{mg} / \mathrm{gEc}$ quando houve agitação no preparo da infusão.

Independente do método de preparo, os resultados obtidos neste estudo demonstraram diferenças significativas nos teores dos bioativos analisados tanto com relação às marcas testadas quanto nas amostras em sachês e a granel.

TABELA 1. Polifenóis totais em amostras preparadas por infusão do chá verde a granel, preparadas com e sem agitação, resultados expressos em $\mathrm{mg} / \mathrm{g}$ de erva seca, equivalentes a epicatequina.

\begin{tabular}{|c|c|c|c|c|}
\hline Marcas & $\begin{array}{c}\text { Polifenóis totais, sem } \\
\text { agitar }\end{array}$ & desvio padrão & $\begin{array}{c}\text { Polifenóis totais, com } \\
\text { agitação }\end{array}$ & desvio padrão \\
\hline 1 & $17,85^{\mathrm{e}}$ & 2,27 & $60,87^{\circ}$ & 0,51 \\
\hline 2 & $26,12^{\mathrm{b}}$ & 0,97 & $53,17^{d}$ & 0,58 \\
\hline 3 & $24,86^{\mathrm{bc}}$ & 0,09 & $45,31^{\dagger}$ & 0,47 \\
\hline 4 & 20,16 de & 0,67 & $62,52^{\mathrm{b}}$ & 0,71 \\
\hline 5 & $42,71^{a}$ & 1,16 & $65,71^{a}$ & 0,37 \\
\hline 6 & 9,97 & 0,43 & $25,47^{j}$ & 0,21 \\
\hline 7 & $22,58^{\mathrm{cd}}$ & 0,39 & $36,29 \mathrm{~g}$ & 0,73 \\
\hline 8 & $25,55^{\text {bc }}$ & 0,07 & $33,17^{\mathrm{h}}$ & 0,40 \\
\hline 9 & $9,63^{f}$ & 0,60 & $50,03^{e}$ & 0,07 \\
\hline 10 & 6,349 & 0,25 & 27,47 & 0,29 \\
\hline 11 & $9,20^{\prime g}$ & 0,36 & 23,75 & 0,29 \\
\hline
\end{tabular}

*Médias seguidas pela mesma letra, numa mesma coluna, não diferem estatisticamente entre si pelo Teste de Tukey ao nível de $5 \%$ de probabilidade. 
TABELA 2. Flavonoides em amostras de infusão de chá verde a granel, preparadas com e sem agitação, resultados expressos em $\mathrm{mg} / \mathrm{g}$ de erva seca, equivalentes a epicatequina.

\begin{tabular}{ccccc}
\hline Marcas & $\begin{array}{c}\text { Flavonoides, } \\
\text { sem agitar }\end{array}$ & desvio padrão & $\begin{array}{c}\text { Flavonoides, } \\
\text { com agitação }\end{array}$ & desvio padrão \\
\hline $\mathbf{1}$ & $3,7^{\circ}$ & 3,69 & $23,36^{\circ}$ & 0,45 \\
$\mathbf{2}$ & $6,02^{\circ}$ & 0,48 & $23,66^{\circ}$ & 0,42 \\
$\mathbf{3}$ & $6,21^{\circ}$ & 1,12 & $18,65^{\circ}$ & 0,17 \\
$\mathbf{4}$ & $4,58^{\circ}$ & 2,24 & $17,25^{\circ}$ & 0,03 \\
$\mathbf{5}$ & $13,31^{\circ}$ & 4,66 & $25,93^{\circ}$ & 0,69 \\
$\mathbf{6}$ & $2,39^{\circ}$ & 4,33 & $10,88^{\mathrm{h}}$ & 0,47 \\
$\mathbf{7}$ & $6,71^{\circ}$ & 16,07 & $13,29^{\circ}$ & 0,41 \\
$\mathbf{8}$ & $6,09^{\circ}$ & 1,28 & $11,51^{\mathrm{h}}$ & 0,66 \\
$\mathbf{9}$ & $9,59^{\circ}$ & 0,96 & $20,73^{\circ}$ & 0,22 \\
$\mathbf{1 0}$ & $4,57^{\circ}$ & 0,32 & $28,62^{\circ}$ & 0,36 \\
$\mathbf{1 1}$ & $6,69^{\circ}$ & 1,44 & $9,41^{\circ}$ & 0,24 \\
\hline
\end{tabular}

*Médias seguidas pela mesma letra, numa mesma coluna, não diferem estatisticamente entre si peloTeste de Tukey ao nível de $5 \%$ de probabilidade.

TABELA 3. Teores de polifenóis totais em amostras de chá verde em sachês, preparadas por infusão com e sem agitação mecânica, resultados expressos em $\mathrm{mg} / \mathrm{g}$ de erva seca, equivalentes a epicatequina.

\begin{tabular}{|c|c|c|c|c|}
\hline Marcas chás & $\begin{array}{c}\text { Polifenóis totais, sem } \\
\text { agitação }\end{array}$ & desvio padrão & $\begin{array}{c}\text { Polifenóis totais, com } \\
\text { agitação }\end{array}$ & desvio padrão \\
\hline 1 & $38,34^{d}$ & 0,35 & $47,91^{f}$ & 0,40 \\
\hline 2 & $28,29 g$ & 0,52 & $35,99^{n}$ & 0,57 \\
\hline 3 & 24,54 & 0,86 & $57,09^{d}$ & 0,36 \\
\hline 4 & $33,95^{e}$ & 0,40 & $52,06^{e}$ & 0,06 \\
\hline 5 & $52,65^{a}$ & 0,96 & $57,97^{\mathrm{cd}}$ & 0,06 \\
\hline 6 & $52,25^{a}$ & 0,54 & $63,99^{a}$ & 0,31 \\
\hline 7 & $43,92^{\circ}$ & 0,39 & $61,69^{b}$ & 0,35 \\
\hline 8 & $27,04^{\mathrm{gh}}$ & 0,51 & $36,42^{\mathrm{h}}$ & 0,11 \\
\hline 9 & $46,24 b$ & 0,68 & 58,57 。 & 0,16 \\
\hline 10 & $26,54^{\mathrm{h}}$ & 0,23 & $39,41^{g}$ & 0,11 \\
\hline 11 & 24,69 & 0,49 & 31,14 & 0,48 \\
\hline 12 & $23,18^{i}$ & 0,23 & $30,13^{i}$ & 0,15 \\
\hline 13 & $28,57^{\text {fg }}$ & 0,94 & $35,80^{\mathrm{h}}$ & 0,32 \\
\hline 14 & $30,13^{f}$ & 0,25 & $39,31^{9}$ & 0,16 \\
\hline
\end{tabular}

*Médias seguidas pela mesma letra, numa mesma coluna, não diferem estatisticamente entre si pelo Teste de Tukey ao nível de $5 \%$ de probabilidade.

Resultados obtidos por Komes et al. (2010) sugerem diferenças significativas na composição química dos chás verdes disponíveis no comércio europeu. No referido estudo observou-se que a eficiência da extração destes compostos depende fortemente das condições da extração e que para obter teores similares dos referidos compostos utilizando água à $80^{\circ} \mathrm{C}$, como solvente extrator, seria necessário um tempo de 5 minutos para a amostra pulverizada, 15 minutos para as amostras envoltas em sachês e 30 minutos para as amostras de folhas a granel. Na temperatura de extração a $100^{\circ} \mathrm{C}$ foram atingidos os teores mais elevados de polifenóis $(35,85 \mathrm{mg} / \mathrm{g}$ equivalentes ao ácido gálico) e flavonoides $(28,65 \mathrm{mg} / \mathrm{g}$ equivalentes ao ácido gálico) para as amostras em sachês.

Para o consumo humano, os chás são, geralmente, preparados por meio da infusão de folhas (a granel) ou em sachês em água inicialmente em ebulição. Por outro lado, em geral, a maioria dos trabalhos científicos empregam solventes orgânicos no processo de extração dos compostos 
TABELA 4. Teores de flavonoides em amostras de infusões de chá verde de sachês, preparadas com e sem agitação, resultados expressos em mg/g de erva seca, equivalentes a epicatequina.

\begin{tabular}{|c|c|c|c|c|}
\hline Amostras & $\begin{array}{l}\text { Flavonóides, } \\
\text { sem agitação }\end{array}$ & desvio padrão & $\begin{array}{l}\text { Flavonóides, } \\
\text { com agitação }\end{array}$ & desvio padrão \\
\hline 1 & $11,37^{e}$ & 3,85 & 20,49 e & 0,27 \\
\hline 2 & 7,06 & 1,28 & $21,93^{d}$ & 0,36 \\
\hline 3 & $7,35^{i}$ & 1,92 & $27,96^{\mathrm{ab}}$ & 0,19 \\
\hline 4 & $10,47^{f}$ & 0,48 & $26,88^{\circ}$ & 0,07 \\
\hline 5 & $12,51^{\mathrm{d}}$ & 1,60 & $25,05^{c}$ & 0,80 \\
\hline 6 & $16,41^{\text {a }}$ & 0,70 & $28,23^{a}$ & 0,52 \\
\hline 7 & $13,77^{\circ}$ & 0,21 & $25,46^{c}$ & 0,33 \\
\hline 8 & 7,42 & 0,16 & $16,24^{\mathrm{g}}$ & 0,75 \\
\hline 9 & $14,47^{\mathrm{b}}$ & 0,80 & $28,16^{a}$ & 0,32 \\
\hline 10 & $8,43^{n}$ & 0,32 & $17,51^{f}$ & 0,85 \\
\hline 11 & $6,81^{i j}$ & 1,12 & $14,29^{n}$ & 0,22 \\
\hline 12 & $6,37 \mathrm{i}$ & 0,32 & $14,63^{\mathrm{h}}$ & 0,43 \\
\hline 13 & $8,99_{\mathrm{gh}}$ & 1,92 & $16,3^{g}$ & 0,47 \\
\hline 14 & 9,279 & 0,32 & $17,47^{f}$ & 0,41 \\
\hline
\end{tabular}

*Médias seguidas pela mesma letra, numa mesma coluna, não diferem estatisticamente entre si pelo Teste de Tukey ao nível de $5 \%$ de probabilidade.

fenólicos, tais como metanol, acetona, etanol e outros. Autilização de diferentes solventes orgânicos dificulta a comparação dos resultados dos diferentes trabalhos publicados. Além disso, dificulta a quantificação do teor de bioativos que o consumidor ingere devido às diferenças de teores extrativos obtidos para cada tipo de solvente utilizado.

Em algumas das embalagens dos chás analisados neste estudo constava a recomendação para não ferver o chá durante a preparação e não deixar mais que 10 minutos em infusão para não ficar excessivamente amargo. O que está de acordo com o preconizado por Pereira et al. (2009), o qual obteve aumento significativo nos teores de polifenóis totais e flavonoides com a elevação do tempo de aquecimento na preparação da infusão de chá verde, pois com o aumento da extração de polifenóis o chá adquire sabor mais marcante e adstringente, podendo torná-lo amargo.

A partir dos resultados apresentados na Tabela 5, é possível observar que a proporção peso seco da planta em relação à quantidade de água utilizada têm influência decisiva na quantidade de compostos fenólicos totais e flavonoides nas infusões.

Contudo, nos trabalhos que avaliam a qualidade do chá verde não foi encontrado nenhum estudo que fizesse a correção do teor de polifenóis totais e flavonoides de acordo com a massa do sachê e o volume de água indicado para o preparo do extrato aquoso. Pode-se observar na Tabela 5 que, seguindo a recomendação de preparo, no que diz respeito ao volume de água utilizado por sachê, as variações são significativas quando compara-se os valores corrigidos aos valores calculados levando em consideração apenas a massa de planta seca por volume de água utilizado para a execução das análises. Isso ocorre porque as diferentes marcas de chá verde apresentam massas diferentes por sachê. Além disso, algumas marcas indicam para o preparo adição de volume diferente dos $200 \mathrm{~mL}$ que deveria ser padrão.

Outro fator que pode influenciar no teor final de bioativos é o tempo de infusão, que neste trabalho foi padronizado em 10 minutos, por ser o tempo no qual ocorre a extração apresentando maiores teores de bioativos. Porém nas embalagens dos chás o tempo sugerido é variável, embora haja predominância da indicação da infusão por 3 minutos.

Uma vez que a atividade biológica da planta está diretamente relacionada à qualidade e quantidade dos bioativos presentes no material vegetal, a falta de padronização observada nos métodos de preparação e quantificação dificulta a comparação entre os resultados dos estudos disponíveis.

Em estudo realizado por Naithani et al. (2006), os autores verificaram perda considerável de fitoquímicos durante o armazenamento do chá verde por 15 meses, e foi levantado o questionamento a respeito da disponibilidade de informação nas embalagens dos chás com relação à perda de bioativos durante o armazenamento e sua consequente influencia no decaimento da atividade 
funcional, tal como a atividade antioxidante.

Para permitir a comparação do teor real de polifenóis e flavonoides entre as marcas analisadas, foi realizado um cálculo de correção levando em consideração o peso médio do conteúdo efetivo dos sachês (quantidade do produto realmente contida na embalagem do produto pré-medido) e a proporção de erva seca/200mL de água. Conforme observado na Tabela 5, a proporção de erva seca/água utilizada no preparo do chá varia de acordo com a marca, pois apesar de haver uma certa padronização quanto a quantidade de água utilizada por sachê, no preparo das infusões, o conteúdo nominal de planta seca dos sachês (quantidade indicada na embalagem do produto) variaram significativamente entre as marcas.

Outro fator que pode influenciar no teor final de bioativos das infusões é o conteúdo efetivo médio dos sachês (quantidade do produto realmente contida na embalagem do produto pré-medido), divergindo conteúdo nominal do produto (quantidade indicada na embalagem do produto). Na avaliação do conteúdo dos sachês, os resultados de peso médio obtidos foram comparados com o indicado nas embalagens. De acordo com os resultados apresentados na Tabela 6 , foi constatado que apenas $50 \%$ das 14 marcas avaliadas estavam dentro dos valores permitidos pela Lei n9933, de 20 de dezembro de 1999, Portaria Inmetro n96, de 07 de abril de 2000 e Portaria do Inmetro n 248 de 17 de julho de 2008, que permite uma tolerância de variação de até $9 \%$ em relação ao peso total de cada sachê (BRASIL, 1999; 2000 e 2008).

\section{CONCLUSÕES}

Os resultados obtidos neste trabalho permitem inferir que existe grande variação nos teores de polifenóis e flavonoides entre as marcas de chá verde analisadas e comercializadas em Salvador-Ba. Foi constatado também que as amostras preparadas por infusão aquosa sob agitação mecânica apresentaram teores de compostos bioativos mais elevados em relação às amostras que não foram submetidas à agitação.

Os resultados deste estudo apontam a necessidade de se estabelecer parâmetros mínimos de bioativos (polifenóis e flavonoides) por grama de matéria seca para infusão aquosa de chá verde visando facilitar a padronização e contribuir para a melhoria da qualidade dos chás verde disponíveis para o consumidor.

TABELA 5. Teores de polifenóis totais e flavonoides, em infusões de chá verde, corrigidos de acordo com a equivalência relativa ao peso médio do conteúdo dos sachês; teores de polifenóis e flavonoides sem correção para efeito de comparação com os valores corrigidos e recomendações de preparo das infusões de acordo com o indicado em cada marca analisada.

\begin{tabular}{|c|c|c|c|c|c|c|}
\hline Marcas & $\begin{array}{l}\text { Peso } \\
\text { médio/ } \\
\text { sachê }\end{array}$ & $\begin{array}{l}\text { Polifenóis } \\
\text { totais (mg } \\
\text { Ec/g), } \\
\text { corrigidos }\end{array}$ & $\begin{array}{l}\text { Polifenóis } \\
\text { totais(mg } \\
\text { Ec/g), sem } \\
\text { correção }\end{array}$ & $\begin{array}{l}\text { Flavonóides } \\
\text { (mg Ec/g), } \\
\text { corrigidos }\end{array}$ & $\begin{array}{c}\text { Flavonóides } \\
\text { (mg Ec/g), sem } \\
\text { correção }\end{array}$ & $\begin{array}{c}\text { Recomendação do preparo na } \\
\text { embalagem } \\
\text { sachê/volume }(\mathrm{mL}) / \\
\text { tempo de infusão }\end{array}$ \\
\hline 1 & 2,29 & $43,89 c$ & $38,34^{d}$ & $13,02^{c}$ & $11,37^{e}$ & $200 \mathrm{~mL} / 2-5 \mathrm{~min}$ \\
\hline 2 & 1,91 & $27,01^{g}$ & 28,299 & $6,74^{\mathrm{gh}}$ & 7,06 & $200 \mathrm{~mL} /$ até adquirir cor e sabor \\
\hline 3 & 1,9 & $23,30^{\mathrm{h}}$ & 24,54 & 6,98 & $7,35^{i}$ & $200 \mathrm{~mL} /$ até adquirir cor e sabor \\
\hline 4 & 1,08 & 18,33 & $33,95^{\mathrm{e}}$ & 5,65 & $10,47^{f}$ & $200 \mathrm{~mL} / 10 \mathrm{~min}$ \\
\hline 5 & 1,25 & 32,90 & $52,65^{\mathrm{a}}$ & $7,81^{f}$ & $12,51^{\mathrm{d}}$ & $200 \mathrm{~mL} / 3 \mathrm{~min}$ \\
\hline 6 & 1,54 & $40,23^{d}$ & $52,25^{a}$ & $12,63^{c}$ & $16,41^{a}$ & $200 \mathrm{~mL} / 3 \mathrm{~min}$ \\
\hline 7 & 1,62 & $35,57 \mathrm{e}$ & $43,92^{c}$ & $11,15^{\mathrm{d}}$ & $13,77^{\circ}$ & $200 \mathrm{~mL} /$ até adquirir cor e sabor \\
\hline 8 & 1,56 & $21,08^{i j}$ & $27,04^{\text {gh }}$ & 5,78 & 7,42 & $200 \mathrm{~mL} / 3 \mathrm{~min}$ \\
\hline 9 & 2,14 & $49,47^{a}$ & $46,24 b$ & $15,48^{a}$ & $14,47^{\mathrm{b}}$ & $200 \mathrm{~mL} /$ até adquirir cor e sabor \\
\hline 10 & 1,59 & $21,10^{\mathrm{ij}}$ & $26,54^{\mathrm{h}}$ & $6,69^{g h}$ & $8,43^{n}$ & $200 \mathrm{~mL} / 3 \mathrm{~min}$ \\
\hline 11 & 1,83 & $22,59^{\mathrm{hi}}$ & 24,69 & $6,22^{\mathrm{hi}}$ & $6,81^{i j}$ & $200 \mathrm{~mL} / 3 \mathrm{~min}$ \\
\hline 12 & 1,76 & 20,39 & 23,18 & 5,60 & 6,37 & $200 \mathrm{~mL} / 3 \mathrm{~min}$ \\
\hline 13 & 2,21 & $31,57^{f}$ & $28,57^{\text {fg }}$ & $9,93^{e}$ & $8,99^{g h}$ & $200 \mathrm{~mL} / 2-3 \mathrm{~min}$ \\
\hline 14 & 2,03 & $47,05^{b}$ & $30,13^{f}$ & $14,47^{\mathrm{b}}$ & 9,279 & $130 \mathrm{~mL} / 3 \mathrm{~min}$ \\
\hline
\end{tabular}

*Médias seguidas pela mesma letra, numa mesma coluna, não diferem estatisticamente entre si pelo Teste de Tukey ao nível de $5 \%$ de probabilidade.

Rev. Bras. PI. Med., Campinas, v.17, n.3, p.436-443, 2015. 
TABELA 6. Peso médio dos sachês; peso máximo e mínimo encontrados/sachê e percentual de diferença do peso médio em relação ao peso indicado na embalagem.

\begin{tabular}{cccccc}
\hline Amostras & $\begin{array}{c}\text { g/ sachê indicado na } \\
\text { embalagem }\end{array}$ & $\begin{array}{c}\text { Peso médio dos } \\
\text { sachês }\end{array}$ & Máx. & Min. & $\begin{array}{c}\text { \% diferença em relação ao } \\
\text { peso médio / sachê }\end{array}$ \\
\hline 1 & 2,0 & $2,9^{\text {a }}$ & 2,52 & 1,96 & 14,55 \\
2 & 1,6 & $1,91^{\text {cd }}$ & 1,93 & 1,74 & 19,49 \\
3 & 1,8 & $1,90^{\text {cd }}$ & 2,05 & 1,79 & 5,56 \\
4 & 1,0 & $1,08^{\circ}$ & 1,11 & 1,06 & 8,19 \\
5 & 1,3 & $1,25^{\circ}$ & 1,28 & 1,22 & $-3,64$ \\
6 & 1,5 & $1,54^{\text {f }}$ & 1,59 & 1,43 & 2,69 \\
7 & 1,3 & $1,62^{\text {ef }}$ & 1,71 & 1,28 & 24,96 \\
8 & 1,6 & $1,56^{\text {ef }}$ & 1,58 & 1,55 & $-1,88$ \\
9 & 1,6 & $2,14^{\text {ab }}$ & 2,16 & 2,11 & 33,75 \\
10 & 1,5 & $1,59^{\text {ef }}$ & 1,67 & 1,54 & 6,00 \\
11 & 1,7 & $1,83^{\text {cd }}$ & 1,97 & 1,73 & 8,21 \\
12 & 1,6 & $1,76^{\text {de }}$ & 1,86 & 1,70 & 10,48 \\
13 & 1,8 & $2,21^{\text {ab }}$ & 2,27 & 2,11 & 23,25 \\
14 & 1,6 & $2,03^{\text {bc }}$ & 2,09 & 1,95 & 27,06 \\
\hline
\end{tabular}

*Médias seguidas pela mesma letra, numa mesma coluna, não diferem estatisticamente entre si pelo Teste de Tukey ao nível de $5 \%$ de probabilidade.

\section{REFERÊNCIAS}

ASOLINI, F.C. et al. Atividade antioxidante e antibacteriana dos compostos fenólicos dos extratos de plantas usadas como chás. Brazilian Journal of Food Technology, v.9, n.3, p.209-15, 2006.

BRAGA, T.V. et al. Determinação de massa fresca, massa seca, água e cinzas totais de folhas de Cissus verticillata (L.) Nicolson \& C. E. Jarvis subsp. verticillata e avaliação do processo de secagem em estufa com ventilação forçada. Revista de Ciências Farmarmacêuticas Básica e Aplicada, v.28, n.3, p.287-90, 2007.

BRASIL. Ministério de Desenvolvimento, Indústria e Comércio Exterior. Lei $\mathbf{n}^{\circ} \mathbf{9 . 9 3 3}$, de 20 de dezembro de 1999. Dispõe sobre as competências do Conmetro e do Inmetro. DOU. Poder Executivo. Brasília, DF, 21 dezembro de 1999.

BRASIL. Ministério de Desenvolvimento, Indústria e Comércio Exterior. Instituto Nacional de Metrologia, Normalização e Qualidade Industrial. Portaria $n^{\circ}$ 96, de 07 de abril de 2000. Aprova o Regulamento Técnico Metrológico estabelecendo critérios sobre o controle de Produtos Pré-Medidos comercializados em unidade de massa e volume de conteúdo nominal igual, de lotes de 5 a 49 unidades no ponto de venda. DOU. Poder Executivo. Brasília, DF, 12 abril de 2000.

BRASIL. Ministério da Indústria, do Comércio e do Turismo. Instituto Nacional de Metrologia, Normalização e Qualidade Industrial. Portaria n ${ }^{\circ} 248$ de 17 de julho de 2008. Regulamento Técnico Metrológico que estabelece os critérios para a verificação do conteúdo líquido de produtos pré-medidos com conteúdo nominal igual e comercializados nas grandezas de massa e volume. DOU. Poder executivo. Brasília, DF, 22 julho de 2008.
BUGNO, A. et al. Avaliação da contaminação microbiana em drogas vegetais. Revista Brasileira de Ciências Farmacêuticas, v.41, n.4, p.491-97, 2005.

CHEN, Y. et al. Variation in catechin contents in relation to quality of 'Huang Zhi Xiang' Oolong tea (Camellia sinensis) at various growing altitudes and seasons. Food Chemistry, v.119, p.648-52, 2010.

FRANÇA, I.S.X. et. al. Medicina popular: benefícios e malefícios das plantas medicinais. Revista Brasileira de Enfermagem, v.61, n.2, p.201-08, 2008.

FRIEDMAN, M. et al. Stability of green tea catechins in commercial tea leaves during storage for 6 months. Journal of Food Science, v.74, n.2, p.47-51, 2009.

JAYASEKERA, S. et al. Variation in antioxidant potential and total polyphenol content of fresh and fully-fermented Sri Lankan tea. Food Chemistry, v.125, p.536-41, 2011.

KOMES, D. et al. Green tea preparation and its influence on the content of bioactive compounds. Food Research International, v.43, p.167-76, 2010.

LEE, K.W. et al. Cocoa has more phenolic phytochemicals and a higher antioxidant capacity than teas and red wine. Journal of Agriculture and Food Chemistry, v.51, p.7292-95, 2003.

LIMA, V.L.A.G. et al. Nota Prévia: Teor de compostos fenólicos totais em Chás Brasileiros. Brazilian Journal of Food Technology, v.7, n.2, p.187-90, 2004.

LIMA, J. D. et al. Chá: aspectos relacionados à qualidade e perspectivas. Ciência Rural, v.39, n.4, p.1258-66, 2009.

MACHADO, C.C.B.; BASTOS, D.H.M. Determinação do perfil de compostos voláteis e avaliação do sabor e aroma de bebidas produzidas a partir da erva-mate (Ilex paraguariensis). Química nova, v.30, n.3, p.51318, 2007.

MATSUBARA, S.; RODRIGUEZ-AMAYA, D.B. Teores de catequinas e teaflavinas em chás comercializados no

Rev. Bras. PI. Med., Campinas, v.17, n.3, p.436-443, 2015. 
Brasil. Ciência e Tecnologia de Alimentos, v.26, n.2, p.401-07, 2006a.

MATSUBARA, S.; RODRIGUEZ-AMAYA, D.B. Conteúdo de miricetina, quercetina e kaempferol em chás comercializados no Brasil. Ciência e Tecnologia de Alimentos, v.26, n.2, p. 380-85, 2006b.

NAITHANI, V. et al. Decline in antioxidant capacity of Indian herbal teas during storage and its relation to phenolic content. Food Research International, v.39, p.176-81, 2006.

NISHIYAMA, M.F. et al. Chá verde brasileiro (Camellia sinensis var assamica): efeitos do tempo de infusão, acondicionamento da erva e forma de preparo sobre a eficiência de extração dos bioativos e sobre a estabilidade da bebida. Ciência e Tecnologia de Alimentos, v.30(Supl.1), p.191-96, 2010.

OWUOR, P.O. et al. The relationship between some chemical parameters and sensory evaluations for plain black tea (Camellia sinensis) produced in Kenya and comparison with similar teas from Malawi and South Africa. Food Chemistry, v.97, n.4, p.644-53, 2006.

PEREIRA, A.V. et al. Determinação de compostos fenólicos em amostras comerciais de chás verde e preto - Camellia sinensis (L.) Kuntze, Theaceae. Acta Scientiarum. Health Sciences, v.31, n.2, p.119-24, 2009.

PERON, A.P. et al. Avaliação do potencial citotóxico dos chás de Camellia sinensis L. e Cassia angustifolia vahl em sistema teste vegetal. Arquivos de Ciências e Saúde Unipar, v.12, n.1, p.51-54, 2008.

PERVA-UZUNALIC, A. et al. Extraction of active ingredients from green tea (Camellia sinensis): extraction efficiency of major catechins and caffeine. Food Chemistry, v.96, p.597-605, 2006.
RAMIREZ-MARES, M.V. et al. In vitro chemopreventive activity of Camellia sinensis, Ilex paraguariensis and Ardisia compressa tea extracts and selected polyphenols. Mutation Research, v.554, p.53-65, 2004.

RAVICHANDRAN, R. \& PARTHIBAN, R. Changes in enzyme activities (PPO and PAL) with type of tea leaf \& during black tea manufacture and the effect of enzyme supplimentation of dhool on black tea quality. Food Chemistry, v.62, n.3, pp. 277-81, 1998.

ROCHA, L.O. et al. Análise da contaminação fúngica em amostras de Cassia acutifolia Delile (sene) e Peumus boldus (Molina) Lyons (boldo-do-Chile) comercializadas na cidade de Campinas. Revista brasileira de ciências farmacêuticas, v.40, n.4, p.522-23, 2004.

SCOTTI, L. et al. Modelagem molecular aplicada ao desenvolvimento de moléculas com atividade antioxidante visando ao uso cosmético. Revista Brasileira de Ciências Farmacêuticas, v.43, n.2, p.153-66, 2007.

SINGLETON, V.L; ROSSI, J.A. Colorimetric of total phenolics with phosphomolybdic-phosphotungstic acid reagents. American Journal Enology and Viticulture, v.16, n.3, p.144-46, 1965.

SOARES, S.E. Ácidos fenólicos como antioxidantes. Revista de Nutrição, v.15, n.1, p.71-81, 2002.

TANAKA, T. \& KOUNO, I. Oxidation of tea catechins: chemical structures and reaction mechanism. Food Science and Technology Research, v.9, n.2, p.12833, 2003.

VEIGA JUNIOR, V.F. et al. Plantas medicinais: cura segura? Química Nova, v.28, n.3, p.519-28, 2005.

VUONG, Q.V. et al. The content of bioactive constituents as a quality index for Vietnamese teas. International Food Research Journal, v.18, p.329-36, 2011. 